\title{
El botín de los vencedores: la doble paradoja de la educación superior "pública" y el Trabajo Social Chileno
}

A pilhagem dos vencedores: o duplo paradoxo da educação superior "pública" e o Serviço Social chileno

The plunder of the winners: the double paradox of "public" higher education and Chilean Social Work

Teresa Matus*

Víctor Orellana**

María Antonieta Urquieta***

\begin{abstract}
Resumen - El artículo desarrolla la siguiente premisa: para hablar de educación superior "pública" en Chile es preciso usar comillas. El desmonte de lo público practicado en Dictadura (años 80 ) y su prolijo perfeccionamiento en los gobiernos civiles (de los ' 90 s hasta el presente) configuran un escenario en lo cual lo que se instala es, más bien, un lucrativo modelo de negocios en reemplazo de un proyecto de educación superior pública para el país. Al colocar como filtro para comprender lo "público" tres requisitos (financiamiento estatal y gratuidad para un porcentaje de estudiantes, procesos democráticos para elecciones internas y propiedad legal pública), la cantidad de universidades efectivamente públicas se reduce drásticamente, engendrando un cuadro paradojal. En ese contexto, la formación universitaria del Trabajo Social chileno expresa una doble contradicción, ya que al contexto de mercantilización de la educación superior se le suma: una distribución asimétrica de cuerpos académicos con nivel de doctorado e investigaciones, la presencia aún mayoritaria de formaciones disciplinarias tradicionales, la existencia de dicotomías clásicas en las propuestas curriculares y también la emergencia minoritaria y consistente de innovaciones y enfoques pluralmente críticos en la formación, tanto en universidades públicas como privadas. Lo anterior no permite sacar conclusiones fáciles o directamente proporcionales en términos de la correspondencia de la crisis de la educación y las respuestas acerca del actual estado de la formación en el Trabajo Social chileno.

Palabras claves: educación superior; política pública; Trabajo Social.
\end{abstract}

Resumo - O artigo desenvolve a seguinte premissa: para falar de educação superior "pública" no Chile é preciso usar aspas. O desmonte do âmbito

\footnotetext{
* Doutora en Trabajo Social de la UFRJ y académica del Dpto. de Trabajo Social en la Universidad de Chile. Email: teresamatus@uchile.cl. ORCID:https://orcid.org/0000-0002-2974-9678.

** Doutor en Trabajo Social de la UERJ. E-mail: v.orellanabravo@gmail.com. ORCID: https://orcid.org/00000002-1257-009X.

*** Doutora en Trabajo Social de la Universidad de Nuevo León en Monterrey, académica del dpto. de Trabajo Social en la Universidad de Chile y, además, actualmente preside la ACHETSU.E-mail: antonieta.urquieta@uchile. cl. ORCID: https://orcid.org/0000-0002-0999-4983.
} 
público praticado na Ditadura (anos 80 ) e seu prolixo aperfeiçoamento nos governos civis (desde os anos 90 até o presente) configuram um cenário no qual o que se instala é, na realidade, um lucrativo modelo de negócios ao invés de um projeto de educação superior pública para o país. Ao inserir como filtro para compreender o "público" três requisitos (financiamento estatal e gratuidade para uma porcentagem de estudantes, processos democráticos para eleições internas e propriedade legal pública), a quantidade de universidades efetivamente públicas se reduz drasticamente, engendrando um quadro paradoxal. Nesse contexto, a formação universitária do Serviço Social chileno expressa uma dupla contradição, já que ao contexto que mercantilização da educação superior se soma: uma distribuição assimétrica de corpos acadêmicos com nível de doutorado e pesquisas, a presença ainda majoritária de formações disciplinares tradicionais, a existência de dicotomias clássicas nas propostas curriculares e também a emergência minoritária e consistente de inovações e enfoques pluralmente críticos na formação, tanto em universidades públicas como privadas. O anterior nos permite chegar a conclusões fáceis ou diretamente proporcionais em termos da correspondência da crise da educação e as respostas sobre o atual estado da formação no Serviço Social chileno.

Palavras-chave: educação superior; política pública; Serviço Social.

\begin{abstract}
The article develops the following premise: to talk about "public" higher education in Chile you need to use quotes. The dismantling of the public sphere practiced during the dictatorship (in the 1980s) and its far-reaching improvement in civilian governments (from the 1990s to the present) configure a scenario in which what is actually a lucrative business model is set up, rather than a public higher education project for the country. By establishing as a parameter to understand the "public" three requirements (state funding and gratuity for a percentage of students, democratic internal election processes, and public legal ownership), the number of effectively public universities is drastically reduced, engendering a paradoxical picture. In this context, the university education of the Chilean social work expresses a double contradiction, since the context that commodifies higher education is added: an asymmetrical distribution of faculty with doctoral degrees and research projects, the presence still in the majority of traditional disciplines, the existence of classic dichotomies in curriculum proposals, and the consistent and minority emergence of innovations and plurally critical approaches to education in both public and private universities. The former allows us to come to easy or directly proportional conclusions in terms of the correspondence of the education crisis and the answers about the current state of education in Chilean social work.
\end{abstract}

Keywords: higher education; public policies; social work.

"Como ha sido siempre la costumbre, el botín de guerra es conducido también en el cortejo triunfal de los vencedores"

Walter Benjamin, Tesis VII

\title{
Un inventario alegórico
}

Comprender la educación pública como un botín de los vencedores es una alegoría benjaminiana para describir un tipo de empresariado que gestó y profita de una naturalización ampliamente extendida actualmente en Chile: el que la educación superior es un mercado. 
Los respectivos dominadores son los herederos de todos los que han vencido una vez. La empatía con el vencedor resulta siempre ventajosa para los dominadores de cada momento. Con lo cual decimos lo suficiente al materialista histórico. Quien hasta el día actual se haya llevado la victoria, marcha en el cortejo triunfal en el que los dominadores de hoy pasan sobre los que también hoy yacen en tierra. Como suele ser costumbre, en el cortejo triunfal llevan consigo el botín. Se le designa como bienes de cultura. En el materialista histórico tienen que contar con un espectador distanciado. Ya que los bienes culturales que abarca con la mirada, tienen todos y cada uno un origen que no podrá considerar sin horror (BENJAMIN, 1989, p. 181).

Como sostiene Matus en su "Punto de fuga" (2018), el carácter intempestivo de lo alegórico queda expuesto especialmente en la forma en la que Benjamin (apud LINDNER, 2014, p. 46) trata a "la mercancía como realización de la intuición alegórica en Baudelaire y reformulando el concepto marxiano de la mercancía".

Es evidente no solo que la alegoría tiene un carácter esquivo, sino que su carácter intempestivo efectúa una crítica a la modernidad. Es decir, hay una doble relación de destrucción: vencer la dificultad de continuidad en los conceptos, como el de mercancía y, a la vez, para transformarlo apoyarse en otra visión crítica de la modernidad. Por eso todas las imágenes de las ruinas, las ciudades como ruinas, la imagen de la mercancía como ruina. Conforme Benjamin:

en vista del encanto fantasmagórico de la mercancía que por primera vez atraviesa toda la sociedad y funde las estructuras de racionalización y abstracción de cambio, hace falta una sensibilidad destructiva, para convertir lo existente en ruinas: se destruye y conserva simultáneamente. La alegoría se aferra a las ruinas. (apud LINDNER, 2014, p. 53).

De esta forma, para Benjamin, el capital, el alma de la mercancía, el fetichismo de la mercancía de Marx, se configura como un tema extendido, troncal, sustantivo, que revela la metafísica del mercado capitalista. Sin embargo,

a diferencia de Marx que en la Crítica de la Economía Política comienza con el fetiche de la mercancía, en Baudelaire se encuentra el fantasma de la cosificación y descosificación de la mercancía. Sobre esto Benjamin sostendrá que la intuición alegórica está construida sobre un mundo fenoménico devaluado. Es esta devaluación específica del mundo de las cosas, la que se manifiesta en la mercancía. (LINDNER, 2014, p. 54).

Por tanto, es todo el mundo de la modernidad el que se ha vuelto totalizado por el aumento dominante del influjo económico de la mercancía, no solo el incremento del capital sino una nueva configuración de mundo. Es otro mundo el que se traza y se resignifica ante la metafísica del capital y 


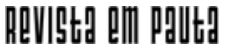

\} EL BOTÍN DE LOS VENCEDORES - MATUS, T.; ORELLANA, V.; URQUIETA, M. A. \}

DOI: $10.12957 /$ REP.2019.45215

la mercancía. Es este mundo el que sale al encuentro de la crítica alegórica, que Benjamin responde a través del flâneur. Es él quien se compenetra como nadie con ese fetiche mercantilizado: "como alegórico, reconoce la etiqueta del precio con la que la mercancía entra en el mercado. Un infierno bulle en el alma de la mercancía que, sin embargo, aparentemente, encuentra en el precio su paz" (BENJAMIN apud LINDNER, 2014, p. 54).

Hay allí un reconocimiento de discontinuidad, de disociación entre el valor de cambio y el valor de uso:

el nuevo tipo de consumidor es el comprador cuyos templos son los pasajes, las grandes tiendas y las exposiciones mundiales [...]. Es solo como mercancía que la cosa ejerce su efecto de alienar a los hombres entre sí. En la empatía con el valor de cambio de la mercancía reside lo decisivo. El lamento por el poder corruptor del dinero es mucho más antiguo que el capitalismo moderno, pero la maldición de que el tiempo es dinero le es propia. (BENJAMIN apud LINDNER, 2014, p. 55).

Interesante la anticipación incluso nihilista sobre el tiempo que recogerá mucho después Cioran (2011), donde también un talante melancólico lo hará expresar lo crucial de esta totalización de tiempo y dinero.

Lo más original de Benjamin es incluir dentro de esta trama de despojo no solo a los sujetos que por cesantía, vejez, limitación educacional o laboral no se encuentran dentro de la vorágine de la producción, sino observar que: "es la propia mercancía quien no posee un tiempo histórico, ella es tiempo vacío y solo el dinero puede redimirla de su irrealidad. El alma de la mercancía contiene una irredención infernal" (BENJAMIN, 2014, p. 56).

Esta inversión, es algo que Benjamin se encargará de resaltar: "no son los hombres los que se apropian de las mercancías producidas por ellos, sino que éstas en su camino de circulación hacia el dinero se apropian del hombre" (apud LINDNER, 2014, p. 58).

Es indudable que estas reflexiones sobre una inversión entre hombres y mercancías conllevan un horizonte temporal extenso y resaltan en Benjamin, como ya proponía Adorno (1962, p. 244-259): "ese concepto hegeliano clave de segunda naturaleza, como objetivación de relaciones humanas alienadas a sí mismas y la categoría marxista de fetichismo de la mercancía".

Lo clave es entender, como propone Lindner (2014), que Benjamin en vez de oponerse irreconciliablemente a la cosificación, se conjura con ella, demostrando claramente un rasgo antisubjetivo. Es decir, para él las cosas delatan algo, nos hacen guiños, dan señales.

Resultaría apasionante hacer un análisis de las cosas y sus manifestaciones entre Benjamin y la inspiración poética de Kavafis (2010), donde precisamente en "Señales" nos advierte sobre la imposibilidad humana de percibirlas, porque nos hemos alejado de las cosas y de sus propias ad- 


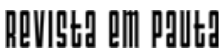

\} EL BOTÍN DE LOS VENCEDORES - MATUS, T.; ORELLANA, V.; URQUIETA, M. A. \}

DOI: $10.12957 /$ REP.2019.45215

vertencias en tal magnitud que ellas nos sorprenden y no las vemos venir. De allí se desprende una tarea: entender las cosas mediante imágenes, volver a habitarlas, teniendo en cuenta que ellas no pueden simplemente ser "interpretadas", porque requieren de una imagen que permita cristalizar un instante de una constelación fugaz.

Es relevante el uso en esto de la noción hegeliana de "momento", ya que no es el resultado de una larga reflexión sino de una intuición que nos conmociona como un relámpago. Para Benjamin, desde allí puede desplegarse la legibilidad del mundo (LINDNER, 2014). Pero este momento es discontinuo, por eso la gracia consiste en saber vivir y estar delante de cada giro sin perder de vista la cuestión central. Esto es específico, hay que reconfigurar este proceso en cada objeto. No es posible simplemente generalizar ya que hay que considerar que Benjamin "protege sus conceptos de una terminología inflacionaria $y$, por tanto, hay que reconstruir constelaciones en las cuales dicho concepto aparece con otros y con ello gana especificidad histórica" (LINDNER, 2014, p. 23).

Ahora bien, como nos recuerda Duras (2009, p.47), siempre aparecer con otros tiene un precio: "[...] Mirar significa reconocerle al otro su atractivo, su particularidad, y esto siempre es deshonroso [...]". En ese sentido, este marxismo tardío abraza la impureza para sostener el potencial certero de una crítica contemporánea. Y para destruir, abriendo los ojos a las contradicciones sociales actuales, destruye algunas de sus máximas que lo inhabilitan para ejercer su propia discontinuidad.

Más aún, como en Benjammin por todas partes ve caminos, se está siempre en la encrucijada:

el carácter destructivo no se detiene en la encrucijada para elegir un camino determinado, sino porque no tiene meta. Tiene tan pocas necesidades y la mínima sería saber qué es lo que va a ocupar el lugar de lo destruido. Aunque sin meta, no carece completamente de dirección. Hace escombros lo existente, y no por los escombros mismos, sino por el camino que pasa a través de ellos. Su conciencia histórica está marcada por la desconfianza invencible respecto del curso de las cosas. (BENJAMIN, 2004, p. 125).

En esto, se muestra en Benjamin lo que él denomina como punto trigonométrico, que consiste en incorporar dentro de sí la experiencia histórica:

allí se está expuesto a todos los vientos de la historia. Como mensajero de estos vientos, se relaciona con el ángel de la historia. Todo lo que podía ser suyo está expuesto por todos los lados al viento. Como el alegorista, su mirada se dirige al espacio. Solo conoce una consigna: hacer sitio, solo una actividad: despejar. (apud ANDERSSON, 2014, p. 391).

De esta forma, el carácter destructivo no se pierde dentro de un laberinto, tampoco se encuentra en un espacio vacío, es en la encrucijada 


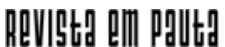

\} EL BOTÍN DE LOS VENCEDORES - MATUS, T.; ORELLANA, V.; URQUIETA, M. A. \}

DOI: $10.12957 /$ REP.2019.45215

donde habita. Y, como en Benjamin, "tampoco toma la destrucción el lugar de lo que merece ser destruido como un camino nuevo, positivo, ni permanece como contraprincipio secundario sometido a lo existente. Al mismo tiempo, el carácter destructivo ordena el lugar como mandatario de una instancia ausente" (apud ANDERSSON, 2014, p. 393).

En este sentido, hay nuevamente acá una preferencia benjaminiana por lo imperfecto, por la idea de que no existe cómo saber elegir el camino correcto, ni tampoco un sujeto correcto o la crítica correcta. Si se recuerda la imagen del hombrecito jorobado, el inquilino de la vida desfigurada es la clave de su análisis: "como indicador de un mundo donde los recipientes ya habían sido rotos, el papel del jorobado es tan paradójico como el del carácter destructivo. Pues, aunque hay caminos no hay en el mundo desfigurado lugares donde sea evidente cómo se puede elegir el camino correcto" (ANDERSSON, 2014, p. 393).

Una cosa sí es cierta: aquellos que se jactan de poseer ese camino, de tenerlo en propiedad, se haber encontrado una crítica correcta, para Benjamin muestran más bien un señuelo, una trampa, una señal para tropezar. De allí que la destrucción "produce un espacio de significado que Benjamin Ilama espacio de imagen revolucionario" (ANDERSSON, 2014, p. 399). Es interesante consignar lo que Andersson (2014, p. 399) enfatiza al respecto: "cuanto Benjamin habla de destrucción dialéctica, lo hace en referencia explícita a la teoría materialista y marxista".

En consecuencia, la destrucción benjaminiana produce un espacio de imagen en el que la pertenencia del colectivo a la realidad histórica se hace visible. Conforme Benjamin (apud ANDERSSON, 2014, p. 400) "solo cuando la transformación de la realidad se vuelve clara en la relación corporal del colectivo con el mundo, se puede hablar de una pertenencia concreta al mundo. Solo entonces se habrá superado la realidad tanto como el Manifiesto Comunista exige". Pero eso no es una meta, no está trazado ni siquiera en un horizonte, es una posibilidad, una senda estrecha que aparece al caminar en la tierra de nadie.

Al contrario de una historia en busca de hechos, en Benjamin (apud ANDERSSON, 2014, p. 406) "el materialista histórico se acerca a un asunto de historia cuando dicho asunto se le presenta como mónada. Es esta estructura reconoce el signo de una detención, de una coyuntura revolucionaria en la lucha a favor del pasado oprimido". Esto es una reacción frente al peligro de una época en la cual todos los parámetros del éxito existencial están coordinados para ocultar el carácter de opresión y de dolor de la historia. De allí la reacción de repudio benjaminiana por la historia de los vencedores, por responder a una concepción de la historia estructural y vacía. En Benjamin (apud ANDERSSON, 2014, p. 409),

la empatía con los vencedores, que es un bastión del historicismo, está unida a la representación que la historia es algo que se puede narrar. Es 


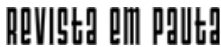

\} EL BOTÍN DE LOS VENCEDORES - MATUS, T.; ORELLANA, V.; URQUIETA, M. A. \}

DOI: $10.12957 /$ REP.2019.45215

característico de la historiografía materialista que se haga estallar el factor épico en el proceso de la construcción. La liquidación del elemento épico debe ser asumido, como lo ha hecho Marx como autor, en El Capital.

Por lo tanto, para el materialista histórico, su tarea es alumbrar, exponer, develar este tiempo ahora, esta historia a contrapelo, colocar en el presente los no cumplidos del pasado. De allí que este artículo busca, desde estos fundamentos, exponer tanto el carácter contradictorio de la educación pública, como el correlato de la educación del Trabajo Social en Chile.

\section{Una educación "pública" entre comillas}

La educación universitaria pública chilena, sin duda, ha sufrido el embate especial de un tipo de neoliberalismo producido en dictadura y perfeccionado en democracia. De allí que se requiera poner su carácter público entre comillas. Tanto es así que el mercado se configura en el fundamento del nuevo escenario de la educación superior en Chile:

la educación universitaria consuma la desigualdad iniciada en la escuela y donde se ejercita eso que Platón llamaba una mentira noble; se acostumbra ver en ella un lugar democrático, pero sus miembros gustan de un inconfesado aristocratismo, como si la Universidad fuera el último refugio de los ideales de una nobleza desinteresada que, al mismo tiempo, provee a sus integrantes beneficios privados, desde el salario hasta los certificados. (BRUNNER; URIBE, 2007, p. 7).

De allí que esa instalación mercantil acuñada en plena dictadura, traspase radicalmente a toda la institucionalidad universitaria, incluyendo no solo a las universidades privadas sino también a la resistencia de las universidades públicas. Entender esa contradicción es clave para pensar críticamente el sistema universitario chileno. El mercado constituye una especie de lo que ya Weber (2009) denominaba Teodicea y que en este sur del mundo se reproduce en la actualidad como una paradoja.

Esto tuvo un punto de inflexión en la dictadura pinochetista que en 1981, a través de la publicación del Decreto Con Fuerza de Ley n. 1, denominada Ley General de Universidades, definió: la limitación de la auto-nomía universitaria (Artículos 3 al 8); el establecimiento de un conjunto de Títulos Profesionales que solo podían desarrollarse dentro de las universidades ya que requieren de la obtención del Grado Académico de Licenciado (Artículos 11, 12 y 13); la autorización para crear universidades privadas, en tanto"personas jurídicas de derecho privado sin fines de lucro" (Artículo 15) y la prohibición de la participación de los funcionarios administrativos y estudiantes en la definición de la gestión y de la dirección de estas nuevas universidades (Artículo 24). 


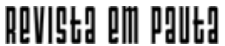

\} EL BOTÍN DE LOS VENCEDORES - MATUS, T.; ORELLANA, V.; URQUIETA, M. A. \}

DOI: $10.12957 /$ REP.2019.45215

Luego, ya en democracia se crea el denominado Consejo de Rectores de Universidades Chilenas, en lo cual se juntan universidades estatales originadas por la fragmentación de la Universidad de Chile y la Universidad Técnica del Estado con las Universidades privadas tradicionales creadas antes de 1981, así como otras que nacieron a partir de éstas. Ya este organismo, que es mixto, se diferencia del resto de universidades privadas fundadas posteriormente a 1981. Tal como desarrolla Mönckeberg (2015), en estas últimas existe una alta variedad de grupos académicos, empresariales nacionales y transnacionales, políticos y religiosos.

En consecuencia, cabe señalar que universidad pública y gratuita, tal como se entiende en Brasil o Argentina, no existe en Chile, ya que incluso la resistencia estudiantil desde el 2011 en sus demandas por gratuidad universitaria tiene resultados asombrosos.

En la última ley de gratuidad universitaria aprobada en el Congreso, no solo su universo es para el $60 \%$ de la población más pobre del país (con la esperanza de subir ese porcentaje según lo permita el crecimiento económico nacional en las próximas décadas), sino que se opera por demanda, sin considerar requisitos de oferta. Es decir, como está pensada desde el estudiante y no es posible discriminar según tipo de postulación universitaria de dicho estudiante, entonces el beneficio de gratuidad se extiende no solo para las universidades públicas, sino para todas aquellas universidades privadas que adhieran a los cánones descritos en la ley.

Con lo anterior, Chile pasa a ser el único país del mundo en que el Estado por vía de una ley de gratuidad estudiantil aporta dinero a las universidades privadas. A ello, se suma un crecimiento estudiantil masivo, que es congruente con otros países de la OECD (Organización para Cooperación y Desarrollo Económico) y que en Chile aumenta de 14,2 al $35,1 \%$ estando lejos aún del promedio de $78 \%$ del resto de los países de esa comunidad. Lo que también crece desde fines de los ochenta son las instituciones universitarias, sobretodo en términos de universidades privadas.

\begin{tabular}{|c|c|c|}
\hline \multicolumn{2}{|c|}{ Total de estudiantes de pregrado en Universidades chilenas al 2018 } \\
\hline Universidades privadas & 348.000 estudiantes & $51,3 \%$ \\
\hline Universidades privadas Cruch* & 144.000 estudiantes & $21,2 \%$ \\
\hline Subtotal Universidades privadas con distinta \\
pertenencia
\end{tabular}

*Consejo de Rectores de las Universidades Chilenas

Fuente: Laval, Ernesto (2019) TIDE desde fuente de Datos Abiertos MINEDUC, Santiago de Chile. 


\section{ReVIStg a d P p putt}

\} EL BOTÍN DE LOS VENCEDORES - MATUS, T.; ORELLANA, V.; URQUIETA, M. A. \}

DOI: $10.12957 /$ REP.2019.45215

Como se deduce del cuadro presentado, las universidades estatales en el Chile del 2018 solo cubren el 27,5\% de toda la matrícula de pregrado. Cabe destacar que las últimas dos universidades estatales, la Universidad de Aysen y la de Rancagua, se crearon en el último gobierno de la presidenta Bachelet y se ubican ambas en regiones sur y centro del país. El 72,5\% restante lo conforman Universidades Privadas con distinta pertenencia. La diferencia es apabullante y el desmedro de los recursos a repartir es asombrosamente paradojal para las universidades públicas.

De esta forma, asistimos a una masividad universitaria nunca antes vista, pero que tiene en el intersticio de sus fundamentos el negocio del lucro, como acertadamente denomina Olivia Mönckeberg (2015) a la forma procedimental de las universidades privadas que hoy con la gratuidad se mezclan con las universidades públicas, ofreciendo un panorama complejo y peculiar.

Pero la paradoja es más profunda aún: si a estos datos - donde las Universidades estatales dentro del Cruch constituyen solo el $27,5 \%$ del total de estudiantes de pregrado - les ponemos como requisito tanto la propiedad legal pública y procesos democráticos para elecciones internas, su porcentaje se reduce al $11 \%$. Si afinamos aún más, solicitando una participación triestamental aunque sea proporcional y una dirección regulada sin re elección indefinida de la rectoría, el porcentaje es tan solo del $2 \%$.

Como es posible apreciar, la naturalización del mercado también opera fundada en una seria precarización democrática de las universidades públicas chilenas. De allí que sea la propia concepción de Universidad la que se coloca en juego en este inventario alegórico y paradojal. Como lo va a expresar Peña, junto con la mezcla de estilos napoleónicos (donde docencia e investigación se fragmentan) y humboldianos (donde supuestamente se cultiva el saber de la época), el nuevo sistema universitario combina: "una orientación al medio o al mercado y la orientación a las disciplinas que cultivan, universidades que compatibilizan el fin de lucro con las rutinas propias de la enseñanza, universidades con adscripción ideológica explícita y aquellas que rehúsan dicha adscripción, universidades de nicho y otras a escala industrial, universidades de propiedad estatal pero controladas por sus profesores y universidades privadas con financiamiento público" (Peña en Brunner y Uribe, 2007, p. 9).

Ahora bien, si en este "mix explosivo en su alegoría" consideramos la distribución de vulnerabilidad social y el ranking escolar de los estudiantes que postulan a las universidades chilenas, observamos lo siguiente (tabela 2).

En la educación superior chilena tienen lugar, por tanto, las así Ilamadas "dinámicas de mercadización", entendidas básicamente como los procesos que ponen a las universidades en situación de mercado (BRUNNER; URIBE, 2007, p. 101). Dicho proceso es acompañado, además, por una forma peculiar de organizar el lucro que podemos identificar con el concepto de lumpenburguesía. 


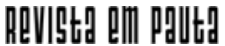

\} EL BOTÍN DE LOS VENCEDORES - MATUS, T.; ORELLANA, V.; URQUIETA, M. A. \}

DOI: $10.12957 /$ REP.2019.45215

Tabla 2 - Perfil de Universidades Chilenas según distribucíon de vulnerabilidad y ranking escolar de estudiantes (Matrícula de pregrado, 2008)

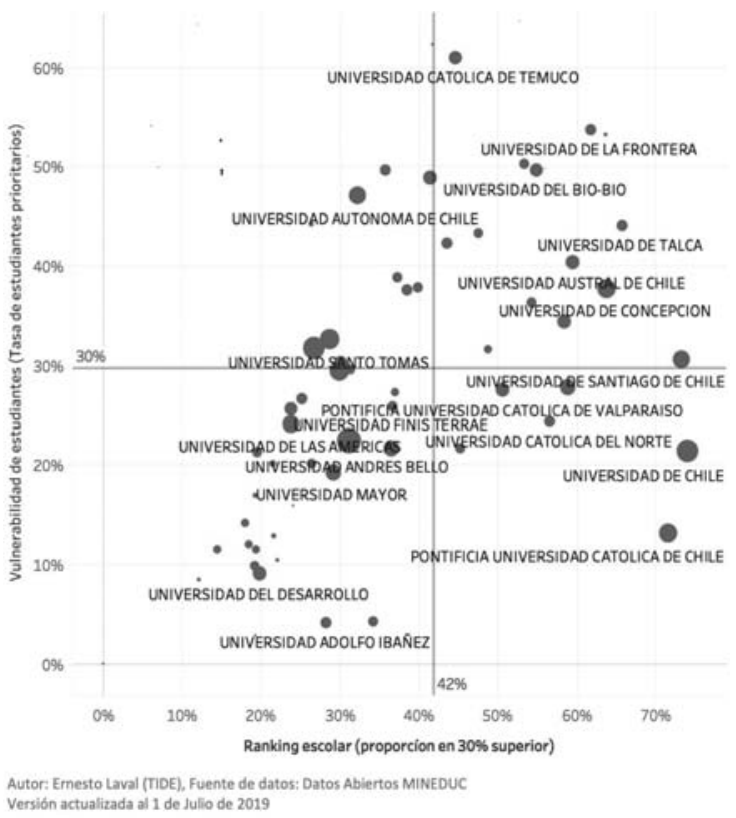

En ese sentido, a partir del análisis propuesto por Beinstein (2016), podemos reconocer tal concepto ya en las descripciones que Marx realizara acerca de la monarquía orleanista de Francia (1830-1848), donde, a propósito de la dominación de la aristocracia financiera, señalaba que

en las cumbres de la sociedad burguesa se propagó el desenfreno por la satisfacción de los apetitos más malsanos y desordenados, que a cada paso chocaban con las mismas leyes de la burguesía, desenfreno en el que, por la ley natural, va a buscar su satisfacción la riqueza procedente del juego, desenfreno por el que el placer se convierte en crápula y en que confluyen el dinero, el lodo y la sangre. La aristocracia financiera, lo mismo en sus métodos de adquisición, que en sus placeres, no es más que el renacimiento del lumpenproletariado en las cumbres de la sociedad burguesa. (MARX, 1966, p. 128-129).

El concepto de "lumpenburguesía", nos informa Beintein (2016), aparece a fines de los años '50 en textos de Ernest Mandel (publicados bajo el pseudónimo de Ernest Germain), para describir a la burguesía de Brasil como una clase semicolonial, "atrasada", no completamente "burguesa" (en el sentido moderno-occidental del término), concepto que es retomado por Gunder Frank (1970), quien lo extendió a las demás burguesías latinoamericanas: 


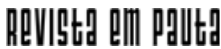

\} EL BOTÍN DE LOS VENCEDORES - MATUS, T.; ORELLANA, V.; URQUIETA, M. A. \}

DOI: $10.12957 /$ REP.2019.45215

Tanto Mandel como Gunder Frank establecían la diferencia entre las burguesías centrales: estructuradas, imperialistas, tecnológicamente sofisticadas y las burguesías periféricas, subdesarrolladas, semicoloniales, caóticas, en fin: lumpenburguesas (burguesías degradadas) (Beinstein, 2016).

Considerando el actual estado de lo público en países como Brasil, Argentina y Chile, se propone alegóricamente tratar el carácter degradado de la educación superior pública bajo la noción de lumpenburguesía, ya que responde a una caracterización peculiar de la naturalización del mercado en la educación universitaria pública. Es decir, será una dinámica de mercadización exitosa y lumpéricamente ordinaria. Eso quita un cierto brillo y coloca precisión estratégica a dicho proceso.

En Chile, por ejemplo, en los sistemas de acreditación, se lleva a cabo la competencia por prestigio, que sería la regla que guía el comportamiento de las decisiones en las que las universidades procuran, de un lado, prestigio académico y social y, del otro, capacidad económica e ingresos (BRUNNER; URIBE, 2007, p. 113). Sin embargo, es posible fundar en evidencias (en denuncias de prensa y en resultados documentados de investigación) que algunas universidades privadas para acreditarse contratan a una gavilla de profesores con Doctorado - incluso con llamados internacionales masivos - mientras dure el proceso de acreditación y luego simplemente "reducen la planta académica, por razones de la empresa". Esto es el estilo "lumpenburgués criollo".

Por otra parte, en la literatura académica se encuentra ampliamente descrito el fenómeno "altruista" de "donar" edificios, laboratorios y pabellones universitarios. Según Brunner y Uribe (2007, p. 113), la explicación económica muestra que el mercado de educación es fuertemente jerárquico y se halla compuesto por un tipo especialísimo de "firmas", descritas por Hansmann (1980, p.23) como empresas, donativo-comerciales sin fines de lucro. En Chile, las investigaciones de Mönckeberg describen brillantemente como opera el proceso mediante el cual universidades privadas se arriendan a sí mismas en su junta de accionistas y directores, tercerizando los edificios y ganando lucro con ello. Esto es el estilo "lumpenburgués criollo".

Un último ejemplo de esta tendencia, que un escritor chileno denominaría como "el peso de la noche" (EDWARDS, 1965) lo constituye la penetración de una cierta forma de concebir los progresos en la vida académica. Ellos se han focalizado en la última década en un estilo gerencial de desempeño, centrándose en la expansión de carreras académicas individuales, que subordinan el sentido en nombre de la cantidad y tipo de publicaciones, produciendo un fenómeno de "isificación" (lo que hoy tendríamos que llamar "wosificación" después de la compra y traspaso del directorio de Thomson Reuter), en lo cual se expande una métrica del significado de calidad asociado a estándares reducidos a ciertos ámbitos y mercados indexados de publicación. Ahora bien, hasta ahí la tendencia es más bien 


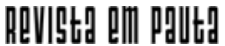

\} EL BOTÍN DE LOS VENCEDORES - MATUS, T.; ORELLANA, V.; URQUIETA, M. A. \}

DOI: $10.12957 /$ REP.2019.45215

universal. Lo criollo radica en el perfeccionamiento de estos nichos reducidos por grupos de estudio en la Comisión Nacional de Investigación y Tecnología conformado por los propios académicos de Ciencias Sociales, que buscan profundizar una fidelidad estricta a ese modelo siendo incluso más rigurosos que grupos de investigadores internacionales de alto reconocimiento. A esto se le suma el "incentivo lumpenburgués" de universidades que pagan a investigadores no importando si pertenecen o no a sus cuerpos académicos estables por publicar y poner en dichos artículos la marca de la universidad en cuestión. Esto ha llevado a desarrollar un mercado interno de pequeña agencia, donde es posible generar flujos de investigaciones a distintos centros.

Todo lo anterior pone en jaque - por una penetración sistémica interna - una forma de educación pública, ya que hoy en Chile no solo sus resistencias están permeadas de este influjo mercantil, sino que se genera una paradoja entre sus discursos alternativos y sus prácticas con claras evidencias de mercantilización. Aún, con todo, este escenario con sus luces y sombras contiene mecanismos que habría que develar y exponer, para poder enunciando, transformarlos.

El punto de inflexión, tal vez, esté puesto precisamente en mirar la educación pública chilena, como diría Yourcenar "con los ojos abiertos" y poder potenciar una mirada lúcida en vez de una suerte de romanticismo estático que no posibilita ver la complejidad del actual escenario. De otro modo, se pelea con enemigos invisibles y se provoca un "duelo de fantasmas". Defender la educación pública universitaria involucra también destruir su iconografía y su estética de corrección y verdad, para dar paso a una destrucción creativa que rompa sus formas y recupere su espíritu.

\section{La doble paradoja de la formación universitaria en el Trabajo Social chileno}

Lo que se postula es que no es posible sostener una visión de Trabajo Social y educación pública como un correlato directamente proporcional, en lo cual uno es el problema y la disciplina es la respuesta. Tampoco es posible trazar un límite de distinción claro entre escuelas públicas y privadas de Trabajo Social en Chile por las siguientes razones: (i) se insertan en el mismo proceso difuso de límites narrado en el punto anterior para la educación pública universitaria; (ii) hay una lógica dicotómica en la visión actual del Trabajo Social Chileno: lo que no logró la dictadura, lo consiguió una lógica dual interna; y (iii) no hay aún un conjunto de investigaciones consistentes que permitan observar los sesgos y matices y ayuden a observar puntos ciegos y áreas difusas.

El punto (i) está desarrollado en el acápite anterior sobre educación pública. Ahora bien, una explicación sobre (ii) es interesante: históricamente, 


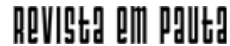

\} EL BOTÍN DE LOS VENCEDORES - MATUS, T.; ORELLANA, V.; URQUIETA, M. A. \}

DOI: $10.12957 /$ REP.2019.45215

no solo el Trabajo Social chileno en su forma universitaria se inaugura en 1925, sino que ya a mediados del siglo XX en 1958 para ser precisos, Chile cuenta con una Asociación Nacional de Escuelas Universitarias de Trabajo Social (hoy ACHETSU). Desde entonces, y atravesando toda la dictadura y las dos primeras décadas de la vuelta a la democracia, esta configuración colectiva mantiene su carácter único y nacional. Sin embargo, después de organizar exitosamente el único Congreso Mundial de Trabajo Social, realizado en Chile en 2006 (El nombre del Congreso fue: Crecimiento y Desigualdad); sobreviene no una consolidación sino un decrecimiento en la legitimidad de esta organización, cuyas causas son multifactoriales. Sin embargo, en vez de criticar y reconstruirla, lo que se va produciendo es una escisión entre esta organización y la emergencia de una asociación de Escuelas de Trabajo Social asociadas al Cruch. Esta última reclama para sí la bandera de la educación pública y reduce la ACHETSU a una "mezcla" público-privada que es rechazada por impura.

Lo clave de esta distinción es que no contiene la necesaria auto observación de la propia "mezcla" público-privada en el seno del Cruch (donde hay escuelas privadas, escuelas confesionales de Trabajo Social, solo que surgidas antes de 1981). Esto lleva a una simplificación que genera una oposición clara pero falsa: hay dos bloques - uno público y otro privado. Eso es de fácil refutación orgánica, porque basta decir que las dos universidades chilenas más antiguas y mejor posicionadas en todos los rankings, como son la Universidad Católica y la Universidad de Chile, están integrando las dos Asociaciones. Sin embargo, hay una refutación más importante y decidora de un escenario difuso en la formación disciplinar en Chile.

En primer lugar, a partir del análisis de las mallas curriculares de todas las Escuelas de Trabajo Social en Chile, es posible afirmar que la formación profesional universitaria se encuentra reducida, mayoritariamente, a "grafías de interpretación tradicionales" de la realidad social (MATUS, 2016 , p. 1). Persiste, en los planos curriculares, una hegemonía conservadora en los fundamentos teóricos y metodológicos de la profesión, lo que permite legitimar, por ejemplo, la predominancia de aproximaciones dicotómicas sobre la relación teoría-práctica, la casi total ausencia de enfoques contemporáneos de Trabajo Social en los planos curriculares y la organización de éstos en las esferas míticas de caso-grupo-comunidad: en 34 de las 40 escuelas, el plano curricular presenta enseñanza de metodologías de Caso, Grupo y Comunidad, en 4 no está presente y en las 2 restantes, éstas esferas han sido reemplazadas por una lógica de micro, meso y macro (MATUS, 2016, p. 11).

Ahora bien, en términos de acreditación, se observa una tendencia invertida de tres tercios, donde las escuelas asociadas al Cruch están acreditadas en $2 / 3$, las privadas lo hacen en $1 / 3$. 


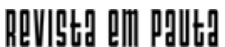

\} EL BOTÍN DE LOS VENCEDORES - MATUS, T.; ORELLANA, V.; URQUIETA, M. A. \}

DOI: $10.12957 /$ REP.2019.45215

Gráfico 1 - Distribución de los programas de pregrado acreditados y no acreditados según tipo de universidad que los ofrece (\%)

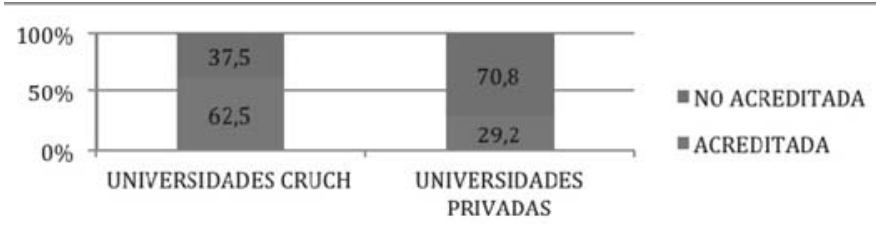

Fuente: Elaboración de la profesora M Antonieta Urquieta para el fundamento formativo de Trabajo Social en la Universidad de Chile

Por su parte, la formación de postgrado, especialmente a nivel de Magíster en Trabajo Social, se inicia en Chile a partir de la década de 2000. Asociado al proceso de expansión de oferta educacional (formación inicial o pregrado), en el área de Trabajo Social, ocurrido en Chile a partir de los años 90, la cual se multiplica rápidamente una década después: en Chile existen alrededor de 78 programas académicos universitarios, que imparten en pregrado en Trabajo Social. Varias poseen sedes regionales ${ }^{1}$ en todo Chile. Lo anterior Ileva asociado también la expansión de espacios de desempeño profesional en instituciones del Estado, ONGs y empresas. Hoy se calcula la existencia de más de 10 mil profesionales ${ }^{2}$ formados a nivel nacional, y en los próximos años, se incrementará rápidamente en más de 20 mil, lo cual muestra un campo potencialmente importante, de demanda para la formación teórica e investigativa en el área disciplinaria. Dicho escenario, sin embargo, no se condice con la escasa disponibilidad o acceso a espacios de formación académica de postgrado ofrecidos en Chile desde 1990 a esta parte. Actualmente existen 13 instancias de formación académica de postgrado en el país aunque solo 3 de esos programas se encuentran actualmente acreditados, a saber: Magíster en Trabajo Social en la Pontificia Universidad Católica de Chile y en la Universidad de la Concepción, y el Magíster en Trabajo Social menciones Familia, Comunidad y Territorios, en la Universidad Católica de Valparaíso.

Además, diversas investigaciones muestran que la enseñanza de la profesión está enfocada principalmente en las áreas donde ésta actúa. Aquello confirma la escasa energía (tiempo, intelecto, investigaciones, publicaciones y debates) que la categoría destina para reflexionar sobre sí misma. Es decir, se privilegia el análisis de las áreas de intervención del Trabajo Social, antes que al Trabajo Social mismo: "De este modo 'ser' trabajador

\footnotetext{
${ }^{1}$ Análisis de posgrado llevado a cabo por la Prof. Paula Vidal para los antecedentes del Magister en Trabajo Social de la Universidad de Chile en 2014.

${ }^{2}$ El Colegio de Asistentes Sociales de Chile cuenta a la fecha con 10.000 colegiados desde su creación. El 11 de octubre de 1955 se publica en el Diario Oficial la Ley n. 11934, que crea el Colegio de Asistentes Sociales de Chile.
} 


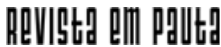

\} EL BOTÍN DE LOS VENCEDORES - MATUS, T.; ORELLANA, V.; URQUIETA, M. A. \}

DOI: $10.12957 /$ REP.2019.45215

social tendría que ver mucho más con el ámbito en que se desempeña que con seleccionar posiciones al interior de un corpus de enfoques en Trabajo Social" (MATUS, 2016, p. 15).

Asimismo, se observa una escasa profundidad teórica de posibles debates que puedan sucederse entre las diferentes escuelas, sus cuerpos académicos y los estudiantes que en esos contextos son formados. En ese sentido, por ejemplo, dos datos son reveladores: en 25 de las 40 escuelas, no existen contenidos de Teoría Social incorporados en la malla curricular; de las 15 restantes, en 9 se enseñan algunos autores contemporáneos, en 3 hay Teorías Generales de la Sociedad, en 3 hay Teorías Sociológica contemporánea (MATUS, 2016, p. 18). Un foco de lo anterior consiste en evidenciar la brecha existente en la formación en Trabajo Social de la disponibilidad de avances epistémicos y tecnológicos disponibles y operables en Ciencias Sociales en Chile y el tipo de didáctica que sigue primando en la formación de las Escuelas de Trabajo Social.

Gráfico 2 - Avances científicos y didáctica existente en las escuelas de Trabajo Social chilenas

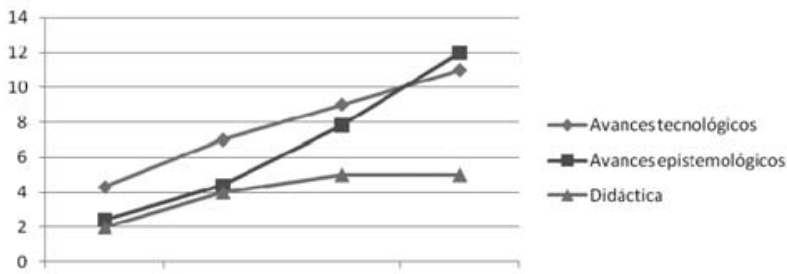

Fuente: elaboración propia en base a 16 investigaciones sobre avances científicos y didáctica existente en las escuelas de Trabajo Social chilenas (Para un mayor análisis ver en referencias)

Lo expuesto también se relaciona con la forma en que se encuentran configurados los cuerpos académicos en las Escuelas de Trabajo Social. Ellos son claramente asimétricos en el sentido de que todavía el estándar de académicos con doctorado y una línea clara de investigación son minoritarios, tanto en escuelas del Cruch como privadas. De allí que todavía en Chile, aún considerando los esfuerzos colectivos de la Red de Investigadores en Trabajo Social, creada en 2015 y conformada por más de cien investigadores repartidos en diversas escuelas del país; no contamos todavía con eso que Lechner denomina "minoría consistente" (1978), que nos permita describir en propiedad las complejidades de la actual configuración de la formación profesional del Trabajo Social en Chile. Este es un panorama difuso y constituye un contexto que en política pública se denomina alegóricamente como un efecto de smoke guns. En este sentido sí podemos decir, con propiedad, que el Trabajo Social chileno de la actualidad es uno donde priman aún características de una disciplina más bien tradicional, pretendidamente neutra y con una pobre reflexión teórica interna. De igual 


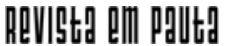

\} EL BOTÍN DE LOS VENCEDORES - MATUS, T.; ORELLANA, V.; URQUIETA, M. A. \}

DOI: $10.12957 /$ REP.2019.45215

modo, sí podemos sustentar que existen, en la actual coyuntura, al menos dos formas en que se manifiesta la hegemonía neoliberal que condicionan la formación y actuación profesional: las políticas sociales, dispuestas para la correcta implementación de la agenda neoliberal, y el modelo de educación superior, privatizado, mercantilizado y totalmente desregulado. Sin embargo, no contamos todavía con evidencias suficientes que nos permitan describir las mediaciones existentes entre esas manifestaciones del neoliberalismo y los procesos de formación y actuación profesional del Trabajo Social chileno en la actual coyuntura histórica.

Para aquello, estimamos que serían necesarias diversas pesquisas que develaran trazos de ese pensamiento neoliberal - que, como primera tarea, habría que conceptualizarlo - en la configuración de los planos curriculares de nuestros procesos de formación: cursos, disciplinas, bibliografías, programas de curso, autores, enfoques, tanto en los fundamentos del Trabajo Social, como en cada uno de los niveles de formación.

\section{Trazos de sentido en una conclusión provisoria}

Entender esa crisis y los puntos ciegos que enfrentan tanto la educación pública como el Trabajo Social en Chile requiere de una loìgica congruente de visioìn. Pero, en la actualidad existe una resistencia al ejercicio de la visioin (JAY, 2007). De lo anterior se desprenden cuatro tipos de consideraciones. La primera es que las formulaciones sobre la visioìn claìsica se han vuelto problemaiticas: la visioìn metafiìsica de lo social, la expresada por un sujeto de gran formato (en diversas tipologiìas de macro-sujeto) desarrollados por los neo historicismos de la visioìn... Además, las recensiones a estos regímenes de la mirada si se llevan al extremo, tienen como resultado una visioìn abatida, desajustada, anacrónica. Lo tercero a considerarse es que si se asume una visión denigrada, concediendo completamente el punto anterior, se pierde la observación como una dimensión sustantiva de posibilidad crítica frente a lo societal. Por fin, se deprende la consideración de que existe un giro (nunca uìnico) de volver a abrir la visioìn como una figura dialeìctica, como una imagen que sabe observar puntos ciegos.

Como ya sostenía Diderot en 1749, en su fenomenal "Carta sobre los ciegos para uso de los que ven", pensar desde puntos ciegos permite esclarecer puntos de vista ya que se despliegan bajo nuevas formas los liìmites que acostumbra a fijar la sociedad (Diderot, 2002). Ahora bien, es indudable que eso contiene un peligro que hay que tomar en cuenta (bien lo sabe Diderot, que fue condenado a varios meses en la caìrcel de Vincennes por dicha carta) y que a eìl lo llevoì a defender aceìrrimamente la libertad, sin descuidar el arte de la reticencia y de la maìscara. Esto uiltimo es una profunda leccioìn en teìrminos de pensar para el Trabajo Social actual un tipo de criìtica travestida (MATUS, 2016). 


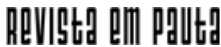

\} EL BOTÍN DE LOS VENCEDORES - MATUS, T.; ORELLANA, V.; URQUIETA, M. A. \}

DOI: $10.12957 /$ REP.2019.45215

Esa criitica seriìa importante porque hoy, junto con las sospechas de la visioìn, ha surgido un enorme descreìdito al denominado proyecto moderno de la Ilustracioìn. Pareciera que esa idea kantiana de ejercer un punto de vista propio sobre la sociedad hubiese sido equivocada o sobrevalorada. En consecuencia, las propias transformaciones del sistema capitalista contienen una fuerza reflexiva que sabe leer y apropiarse de la criìtica: "el sistema capitalista se ha mostrado infinitamente maìs robusto de lo que habiìn pensado sus detractores - Marx en primer lugar -, pero esta robustez se debe tambieìn al hecho de que el capitalismo ha encontrado en sus criiticas la manera de garantizar su supervivencia" (BOLTANSKI; CHIAPELLI, 2002, p. 71-72).

Incluso, aunque la criitica se renueve, es importante considerar que sus propuestas son acotadas frente a un contexto histoìrico. Por tanto, cuando ella consigue deslegitimar procesos anteriores y privarles de su eficacia (como mediante la criìtica a la esclavitud), el capitalismo se rearma encontrando nuevos frentes. Asimismo, cuando la criìtica se plantea como oposicioìn directa al capitalismo, eiste se ve obligado a responder a los ataques de la criitica. Sin embargo, y esto es lo relevante, a pesar de incorporar en ese mecanismo algo de los valores o de las enunciaciones usadas por la criitica, las transforma en parte de sus propios dispositivos. Ejemplar es el uso de semaìnticas asociadas al cambio, a la revolución y a la diversidad en partidarios de las derechas surgidas en los uiltimos diez anPos. En consecuencia, el capitalismo consigue renovar su semaìntica, sin mover un aìpice sus principios basales de acumulacioìn.

El costo que la criitica ha de pagar por ser escuchada, al menos parcialmente, es ver coìmo una parte de los valores que habiìa movilizado para oponerse a la forma adoptada por el proceso de acumulacioìn es puesta al servicio de esta misma acumulacioìn mediante el proceso de aculturación. (BOLTANSKI; CHIAPELLI, 2002, p. 73-74).

Frente a un aumento de la criìtica, el capitalismo se volveriìa maìs reflexivo, permitieindole considerar las senPales que le son enviadas desde la propia criitica, fagocitaìndola con mecanismos de cailculo, de rearme, de seduccioìn. Usando, como ya planteaba Marcuse (1998, p. 23ss), no solo presiones externas, sino colaìndose como presioìn interna. De este modo, lo que tenemos enfrente es un capitalismo que se ha vuelto experto en distinciones, incorporando la criitica incluso en sus propias instancias de coordinacioìn funcional:

la reanudacioìn de la critica viene acompanPada, aunque siempre con retraso, de la aparicioìn de nuevos tipos de dispositivos de protesta dotados de una mayor capacidad de actuar sobre las formas emergentes del capitalismo, de acuerdo con el principio seguìn el cual la crítica, en pos de la eficacia, tiende a volverse isonomiìa de los objetos a los que se aplica. (BOLTANSKI; CHIAPELLI, 2002, p. 640). 


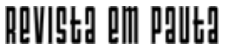

\} EL BOTÍN DE LOS VENCEDORES - MATUS, T.; ORELLANA, V.; URQUIETA, M. A. \}

DOI: $10.12957 /$ REP.2019.45215

Ante este panorama ¿coìmo repensar la criìtica? No de forma tradicional, directa, monoliitica. Su volver a empezar requiere, si el entorno poliitico y tecnoloìgico se lo permite, una incitacioìn a transformarse, confundiendo las reglas del juego (BOLTANSKI; CHIAPELLI, 2002). Por tanto, si el capitalismo captura a la criitica y la transforma en su propio rostro, la criìtica tiene que asumir travestidamente los rostros del capitalismo para poder impactarlo sorpresivamente, indirectamente, explosivamente. Pero, ello exige renunciar a la constatacioìn abierta de la criìtica, a ser reconocida puiblicamente, a pavonearse como criìtica. Asimismo, ese giro reclama de una nueva loìgica, de una criìtica que conozca sus liìmites y que sepa llegar hasta ellos, mirar su propio abismo y configurarse desde eil. Pensar la criitica como una potencia que corroe no solo las formas de pensar sino las propias formas de pensarla.

Esa es la innovación crítica que el Trabajo Social requiere, porque esta dialéctica de la mirada (BUCK MORSS, 1989) impide la reificacioìn de los reìgimenes escoìpicos. En vez de apelar a la fuerza de una sola visioìn monoliitica, promueve un caraìcter abierto y multiplicador. De este modo, cuando la criitica y su innovacioìn se concibe como un relato poliescoìpico: "corremos menos riesgo de caer presa determinada de desarrollo, o de ser petrificados por la mirada medusea y ontologizadora del otro" (JAY, 2008, p.238). del impero maligno de la mipermanecer fijos en el estadio del espejo o en una fase

Es allí donde sería posible un trabajo diverso de investigaciones tanto en relación a la opacidad de la educación universitaria, como de la formación en las escuelas de Trabajo Social chilenas. La loìgica de construccioìn seriìa la de un modelo de investigacioìn de alta integracioìn, en el cual los participantes estén dispuestos a auto observar sus sistemas e innovar en su loìgica y en sus contenidos. Asumir esta posibilidad nos dariìa como resultado: consolidación organizacional en la Asociación Nacional de Escuelas, análisis de los curriculum formativos de las escuelas, crecimiento de calidad de revistas disciplinares, sistemas de investigaciones y de intervención en una lógica de I + D. Este conjunto de innovaciones podría potencialmente configurar una fecha, una piedra, un caballo de Troya para enfrentar los puntos ciegos de la política puìblica, también en materia de educación superior. 


\section{ReVIStg a d P p putt}

\} EL BOTÍN DE LOS VENCEDORES - MATUS, T.; ORELLANA, V.; URQUIETA, M. A. \}

DOI: $10.12957 /$ REP.2019.45215

\section{Referências}

ADORNO, T. Prismas. La crítica de la cultura y la sociedad. Barcelona: Editorial Ariel, 1962.

ANDERSSON, D. Destrucción/Construcción. In: OPITZ, M.; WIZISLA, E. (ed.). Conceptos de Walter Benjamin. Buenos Aires: Las Cuarenta, 2014.

BEINSTEIN, J. Origen y auge de las lumpenburguesías latinoamericanas. Disponible en el sitio web América Latina en Movimiento, https:// www.alainet.org.

BENJAMIN, W. Discursos Interrumpidos I. Buenos Aires, Taurus, 1989.

BENJAMIN, W. Libro de los pasajes. Madrid: Akal, 2004.

BOLTANSKI, L.; CHIAPELLI, E. El nuevo espíritu del capitalismo. Madrid, Akal, 2002.

BUCK MORSS, S. La dialeìctica de la mirada. Madrid: Editorial Trotta, 1989.

BRUNNER, J. J.; URIBE, D. Mercados universitarios: el nuevo escenario de la educación superior. Santiago de Chile: Ediciones Universidad Diego Portales, 2007.

CIORAN. Caídos del tiempo. Madrid: Editorial Tecnos, 2011.

DIDEROT, D. Carta sobre ciegos para uso de los que ven. Valencia: Editorial Pre-Textos, 2002.

DURAS, M. Destruir, dice. Madrid: Tusquets, 2009.

EDWARDS, J. El peso de la noche. Barcelona, Seix Barral, 1965.

GUNDER FRANK, A. Lumpenburguesía: lumpendesarrollo. Montevideo: Ediciones de la Banda Oriental, 1970.

HANSMANN, H.B. The role of Nonprofit Enterprise, Yale Law Journal, 89 April 1980.

JAY, M. Ojos Abatidos. La denigración de la visión en el pensamiento francés del siglo XX. Madrid: Editorial AKAL, 2008.

KAVAFIS, K. Obras completas. Editorial Trotta, Madrid, 2010.

LAVAL. Santiago de Chile: TIDE desde fuente de Datos Abiertos de MINEDUC, 2019.

LINDNER, B. Alegoría. In: OPITZ, M.; WIZISLA, E. (ed.). Conceptos de Walter Benjamin. Buenos Aires: Las Cuarenta, 2014.

MARCUSE, H. El hombre Unidimensional. Editorial Fondo de Cultura Económica, Buenos Aires, 1998.

MARX, K. Las luchas de clases en Francia de 1848 a 1850. In: MARX, K.; ENGELS, F. Obras escogidas. Tomo I. Moscú: Editorial Progreso, 1966. 


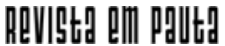

\} EL BOTÍN DE LOS VENCEDORES - MATUS, T.; ORELLANA, V.; URQUIETA, M. A. \}

DOI: $10.12957 /$ REP.2019.45215

MATUS, T. Una criitica travestida para enfrentar al capital. In: MATUS, T. Las caras del Trabajo Social en el Mundo. Santiago de Chile: Editorial RIL, 2017.

MATUS, T. Punto de Fuga. Imágenes dialécticas de la crítica en el Trabajo Social contemporáneo. Tomo II. Buenos Aires: Editorial Espacio, 2018.

MÖNCKEBERG, M. El negocio de las universidades en Chile. Santiago, Debate, 2015.

LECHNER, N. Poder y orden: estrategias de la minoría consistente. En: Revista Mexicana de Sociología 40(4):1201-1258, 1978.

PEÑA, C. Prólogo. En: Brunner, José Joaquín y Uribe, Daniel. Mercados Universitarios: el nuevo escenario de la educación superior. Ediciones Diego Portales, Santiago de Chile. 2007.

WEBER, M. Economía y Sociedad. México: Editorial Fondo de Cultura Económica 8ํㅡㄹ Re edición, 2009.

YOURCENAR, M. Con los ojos abiertos. diálogos con Matthieu Galey Barcelona: Plataforma Editorial, 2008.

Anexo A - Investigaciones sobre Trabajo Social en Chile, desde donde se elaboró el gráfico de referencia:

AGUAYO, C. Fundamentos teóricos de la sistematización. Revista de Trabajo Social UC, nº 61, Santiago, pág. 31-36, 1992.

ALVARIÑO, P; ISRAEL, R. Educación para el Servicio Social. 67 años de historia. Documento mimeografiado cátedra Nidia Aylwin. Santiago, 1992. AYLWIN, N. El taller y la didáctica del Trabajo Social en Chile. Apuntes Universidad Católica de Chile. Santiago, 1997.

AYLWIN, N., OTEMBERGER, A. La metodología científica en Trabajo Social en Chile. Santiago: Apuntes Universidad Católica de Chile, 1999.

HEDERRA, A. Las Escuelas de Servicio Social y la Facultad de Ciencias Sociales de la Universidad de Chile. Vol XIV nº 60-67 Santiago, 1967.

MAIDAGÁN DE UGARTE, V. El Servicio Social de Chile. Revista de Trabajo Social no 14, Universidad Católica de Chile, Santiago, 1975.

MATUS, T, AYLWIN, N y FORTTES, A. La reinvención de la memoria. Santiago: Edición Escuela de Trabajo Social Universidad Católica de Chile, 2004.

MATUS, T. Cuando la epistemología no basta. Revista Acto Social, Buenos Aires, Córdoba, Argentina, no7 Año III, marzo 1994. 


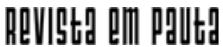

\} EL BOTÍN DE LOS VENCEDORES - MATUS, T.; ORELLANA, V.; URQUIETA, M. A. \}

DOI: $10.12957 /$ REP.2019.45215

MATUS, T; PONCE DE LEÓN, M., MUÑOZ, C. Investigando en Red, Estudios Internacionales en Trabajo Social. Santiago: Editora IASSW/ALAIETS/ ACHETS: LOM Editores, 2009.

MATUS, T; FORTTES, A., AYLWIN, N. Comité de reestructuración curricular Universidad Católica de Chile. Estudio sobre los currículos de las Escuelas de Trabajo Social en Chile, Santiago, 1999.

MATUS, T. Trabajo Social ¿una disciplina en tensión evolutiva? En QUIROZ, M. Antología del Trabajo Social chileno. Concepción: Editora Universidad de Concepción, 1998.

QUEZADA, M., MATUS, T., RODRIGUEZ, N., ONETO, L., PAIVA, D., PONCE DE LEÓN, M. Perspectivas metodológicas en Trabajo Social. Buenos Aires: Editorial Espacio, 2001.

QUIROZ, H. Apuntes para una historia del Trabajo Social en Chile. En: Trabajo Social en algunos países: aportes para su comprensión. NELIA TELLO coordinadora. Universidad Autónoma de México, 2000.

ROMERO, S. La instrumentación del trabajador social. Revista de Trabajo Social UC, nº 61, Santiago, pág. 45-47, 1992.

VALDÉS, X. Las cuentas pendientes de la sistematización. Revista de Trabajo Social UC, nº 61, Santiago, pág. 9-17, 1992.

ZÚÑIGA, R. Sobre el sistematizar. Revista de Trabajo Social UC, no 61, Santiago, pág. 19-29, 1992.

DOI: $10.12957 /$ rep.2019.45215

Recebido em 04 de setembro de 2019.

Aprovado para publicação em 10 de setembrode 2019.

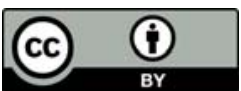

A Revista Em Pauta: Teoria Social e Realidade Contemporânea está licenciada com uma Licença Creative Commons Atribuição 4.0 Internacional. 